\title{
DA AÇÃO DA SAPONINA SÔBRE PEIXES: GUARUS (Poecilia sp.) E ACARÁS (Geophagus sp.)
}

\author{
]. F. Tabarelli Neto e Virgilio Bonoldi
}

Trabalhando no saneamento de zonas do vale do Rio Doce, no Estado de Minas Gerais, Cesar Pinto (*) propõe, após pesquizas levadas a efeito em colaboração com Firmato DE ALMeida - às páginas 291-311 do citado opúsculo um novo método para a profilaxia da esquistosomose mansoni (Schistosoma mansoni (Sambon), 1907). Este novo método prende-se ao fato de serem, não sòmente os caramujos (Australorbis glabratus), hospedadores intermediários do Sclístosoma mansoni, como também as fases evolutivas dêste último, sumamente sensíveis à ação da saponina encontrada em determinadas plantas da região, tais como o cipó timbó (Serjania sp.) e dos frutos de Sapindus saponaria, vulgarmente denominados sabonetes ou saboneteira.

Os autores, em suas pesquizas, eontrolaram a ação tóxica dos macerados de caule seco do cipó timbó, em peixes lambaris (Astyna: bimaculatus (L), 1758), e verificaram, em aquários, ação mortal de tais macerados, quando em concentra๔ỗes equivalentes à soluçôes de saponina a $3 / 1000$, aproximadamente.

Segundo os mesmos pesquisadores, (página 308) "a mortalidade de peixes existentes nos córregos contaminantes, que aliás não são utilizados para a alimentação do homem, tem muito menos importância do que a impressionante incidência da esquistosomose mansoni que na cidade de Itambacuri com 3 mil habitantes, eleva-se a $40-60 \%$, atingindo $85 \%$ na cidade de Fortaleza no Norte de Minas Gerais, $30 \%$ na cidade de Teófilo Otoni, para citar apenas as localidades onde foram feitos estudos sôbre a incidência da referida doença".

Levando em conta essa revivecência do assunto, pois de longa data diversas plantas contendo saponina utilizam-se na pesca, para o que seus extratos são vertidos nas lagôas e riachos, ou mesmo na caça, e neste caso como veneno das flechas, interessamo-nos por esclarecer algumas particularidades da sua ação sôbre os peixes.

As referências que se encontram a propósito de tais substâncias atribuemThes geralmente, como característicos dois fatos: 1) a propriedade de espumar - espuma persistente - quando agitada em soluções aquosas, fenômeno êste aliás cbservável nos outros compostos a elas relacionados; 2) alto poder hemolítico, sendo já quantidade menor do rue a centimilesimal bastante para provocar a libertação do pigmento dos eritrocitos. Bascia-se mesmo nesse alto poder sôbre os gióbulos vermelhos o método mais difundido de dosagem relativa de tais compostos,

(*) Um ano de combate itm denenes paracitírias que atacant os rodoviários da estrada Nio-Bahia, 1942 a 1943. Memorias do Iustituto Oswaido Craz. Tomo 40 - Fasc. 3 - Ano de 1944. 
nos substratos que os possuem (índice hemolítico). Além de tal comportamento consigna-se também sua ação irritativa das mucosas em geral, bem como a atuação sôbre o sistema nervoso com manifestação, inicialmente, sôbre o sistema da condu ção motora, e depois, posteriormente, da sensitiva.

Interessante é a inocuidade das saponinas quando ingeridas, o que assegura o aproveitamento da caça ou pesca, sem conseqüências dêsse particular, e tal como é feito em não poucas regiōes por nativos que utilizam tais venenos para a prática dêsses fins. Aliás, a ação das saponinas como tal se exerce sôbre todos os seres vivos da escala zoológica, e de modo mais eletivo sôbre os da escala inferior. $\mathrm{O}$ que se conhece do aspéto puramente químico da questão não representa o fruto do interêsse direto e sim conseqüência de estarem tais substâncias ligadas a outras que gozam de vantagens terapêuticas, ou seja, aos princípios cardíacos. Formam com êstes e os venenos dos sapos, um grupo de esteróides que se encontram sob a forma de glucosideos (na maioria) relativamente espalhados na natureza. $O$ isolamento e purificação é, de maneira geral, pelo menos até o presente, operação trabalhosa e de resultado precário. Isso não impediu todavia, de se haver esclarecido quais os açúcares que entram na constituição de muitas saponinas bem como o núcleo cíclico (ou ciclo-pentaperhidrofenantreno ou sapotaleno) das suas agluconas. Igualmente sabe-se fornecerem compóstos de adição com álcool ou fenol (1:1) o que se utiliza para sua purificação. Outros dados a elas referentes, sendo particularidades de comportamento, apresentam interêsse restrito.

Interessados então pelo assunto, procuramos verificar com pormenores a ação da saponina sôbre os peixes: e são os fatos observados que passaremos a descrever.

A-fim-de melhor apresentar as nossas experiências, e baseados no que observamos, dividiremos a ação da saponina sôbre os peixes em 5 fases que se sucedem sempre na mesma ordem e com espaços de tempo variáveis, segundo diversos fatores tais como: concentração do tóxico, espécie utilizada, temperatura, etc.

\section{1. ${ }^{\mathrm{a}}$ fase: EXCITAÇÃO}

- na qual os peixes apresentam movimentos natatórios rápidos.

\section{2. fase: ASFIXIAMENTO}

- na qual, após diminuição gradativa da excitação vão procurando a superfície livre do liquido, tentando por vezes saltar fóra do mesmo.

\section{$3 .^{a}$ fase: DEPRESSÃO INICIAL}

- na qual, inertes as nadadeiras, e o mais das vezes com o corpo em posição anormal, começam a se despreender da superfície livre do líquido e, assim, cáem no fundo do aquário. Em seguida, quer expon- 
taneamente, quer por excitação mecânica, voltam a nadar em busca da tôna, fato que se vai reproduzindo com depressão gradativa dos movimentos.

\section{4. ${ }^{\mathrm{a}}$ fase: DEPRESSÃO ADIANTADA}

- na qual, se localizam no fundo do aquário, locomovendo-se às vezes, por meio de movimentos natatórios mui lentos e desordenados. Durante esta fase não respondem à excitação mecânica.

\section{5. ${ }^{\text {a }}$ fase: MORTE}

Os peixes mortos não vêm à tôna e sim permanecem no fundo do aquário.

Em alguns, apesar de não responderem à excitação mecânica e terem seus opérculos completamente parados, a abertura para exame das visceras, para o encontro eventual de algum dado, revelou que persistiam ainda os batimentos cardiacos.

\section{MATERIAL}

Servimo-nos, numa primeira série de experiências, de peixes Guarus (Poecilia sp.) e numa segunda, de Acarás (Geophagus sp.), todos mantidos, à temperatura do laboratório, em aquários que preenchiam integralmente as condições a bôa manutenção dos peixes.

A saponina usada para a experimentação foi a de J. D. Riedel, e as soluções eram despresadas após 48 horas decorridas de sua preparação.

Em duas experiências, para têrmo de comparação, pesquisamos a ação de um macerado aquoso de frutos de saboneteira (Sapindus saponaria). Estes frutos, contêm saponina na porcentagem de $\mathbf{1 2 , 5} \%$ (pág. 299 do trabalho citado). Baseados nesta última proporção fizemos macerar, em $750 \mathrm{~cm}^{3}$ de água a frio e por 24 horas, 6 gramas de frutos, sem as sementes e prèviamente triturados, macerados cuja concentração deve equivaler a uma solução de saponina a 1/1000.

As experiências foram levadas a efeito em aquários comuns de vidro.

Passamos a expor os nossos protocolos.

I) - EXPERIMENTAÇÃo COM GUARUS (Poecilia sp.)

A) Pesquiza com diversas concentrações de saponina, a-fim-de comprovarmos o seu poder tóxico. 
$\left.10^{\circ}\right)$

Saponina pura em solução a $1 / 1000$. Preparação recente.

Número de peixes: 10

Volume líquido: $300 \mathrm{~cm}^{3}$

Temperatura: $20^{\circ} \mathrm{C}$
a) $-1 \cdot^{\mathrm{a}}$ fase: imediatamente após a imersão.
b) $-2 .^{\text {a }}$ fase: aos $6 \mathrm{~m}$.
c) $-3 .^{a}$ fase: aos $10 \mathrm{~m}$.
d) $-4{ }^{\mathrm{a}}$ fase: aos $18 \mathrm{~m}$.
e) - 5..$^{\mathrm{a}}$ fase: Morte: aos $30 \mathrm{~m}$.

$\left.2 .^{\circ}\right)-$

Saponina pura em solução a 1/5000. Preparação recente.

Número de peixes: 10

Volume líquido: $300 \mathrm{~cm}^{3}$

Temperatura: $20^{\circ} \mathrm{C}$
a) $-1 .^{\mathrm{a}}$ fase: aos $5 \mathrm{~m}$.
b) $-2 .^{a}$ fase: aos $20 \mathrm{~m}$.
c) $-3 .^{a}$ fase: aos $60 \mathrm{~m}$.
d) $-4 .^{\mathrm{a}}$ fase: aos $80 \mathrm{~m}$.
e) - 5. fase: Morte: $1 \mathrm{~h} 50 \mathrm{~m}$. após o início.

$\mathrm{Na}$ prova seguinte procuramos verificar se a alimentação tinha influência sôbre a rapidez de ação do tóxico.

3.') -

Saponina pura em solução a 1/2.500. Preparaçâo recente.

Número de peixes: $10 \mathrm{em}$ cada lote

Volume líquido: $300 \mathrm{~cm}^{3}$

Temperatura: $20^{\circ} \mathrm{C}$.

1.') - Lote alimentado

a) $-1 .^{\mathrm{a}}$ fase: aos $4 \mathrm{~m}$.

b) $-2 .^{\mathrm{a}}$ fase: aos $16 \mathrm{~m}$.

c) $-3 \cdot^{a}$ fase: aos $45 \mathrm{~m}$.

d) $-4 .^{\mathrm{a}}$ fase: aos $55 \mathrm{~m}$.

e) $-5 .^{a}$ fase: Mortos: aos $60 \mathrm{~m}$. $\left.2 .^{\circ}\right)$ - Lote não alimentado

a) $-1 .^{\mathrm{a}}$ fase: aos $4 \mathrm{~m}$. Durante esta fase, colocou-se alimento no aquário, o qual não foi apanhado pelos peixes.

b) $-2{ }^{\mathrm{a}}$ fase: aos $12 \mathrm{~m}$.

e) $-3 .^{\mathrm{a}}$ fase: aos $40 \mathrm{~m}$.

d) $-4 \cdot^{\mathrm{a}}$ fase: aos $55 \mathrm{~m}$.

e) $-5 \cdot^{\mathrm{a}}$ fase: Mortos: aos $60 \mathrm{~m}$.

Como vemos, por esta única experiência, não houve variações dignas de registro entre os 2 grupos, a não ser uma rapidez maior na sucessão nas fases iniciais, para os lotes não alimentados, o que entretanto não parece significativo.

B) - Pesquiza com solução de saponina na concentração de 1/1000 em diversas temperaturas.

Saponina pura em solução a $1 / 1000$. Preparação recente.

Volume líquido: $300 \mathrm{~cm}^{3}$. 
$\left.1^{\circ}\right)$ - Temperatura: $15^{\circ} \mathrm{C}$

Número de peixes: 6

a) $-1 .^{\mathrm{a}}$ fase: aos $2 \mathrm{~m}$.

b) $-2 .^{a}$ fase: aos $10 \mathrm{~m}$.

c) $-3 \cdot^{a}$ fase: aos $13 \mathrm{~m}$.

d) $-4 .^{a}$ fase: aos $20 \mathrm{~m}$.

e) $-5 .^{\mathrm{a}}$ fase: $(4$ mortos aos $40 \mathrm{~m}$.

Morte dos 2 restantes aos $50 \mathrm{~m}$.)

$\left.20^{\circ}\right)$ - Temperatura: $20^{\circ} \mathrm{C}$

Número de peixes: 6

a) - $1 .^{\mathrm{a}}$ fase: $1 \mathrm{~m}$. após imersão

b) - ${ }^{a}$ fase: aos $8 \mathrm{~m}$.

c) $-3 \cdot^{\mathrm{a}}$ fase: aos $13 \mathrm{~m}$.

d) $-4 .^{\mathrm{a}}$ fase: aos $17 \mathrm{~m}$.

e) - 5. ${ }^{\mathrm{a}}$ fase: (Todos mortos aos $30 \mathrm{~m}$., menos 1 que morreu aos $40 \mathrm{~m}$.)

$\left.3 .^{\circ}\right)$ - Temperatura: $25^{\circ} \mathrm{C}$ Número de peixes: 6

a) $-1 .^{\text {a }}$ fase: imediatamente após a imersão

b) $-2 \cdot^{\mathrm{a}}$ fase: aos $4 \mathrm{~m}$.

c) $-3 .^{a}$ fase: aos $7 \mathrm{~m}$.

d) $-4 .^{\mathrm{a}}$ fase: aos $15 \mathrm{~m}$.

e) $-5 .^{a}$ fase: (primeiros mortos aos $15 \mathrm{~m}$.

Todos mortos aos $19 \mathrm{~m}$.)

Repetimos estas provas 2 dias depois, utilizando a mesma solução das experiências anteriores, que sofreu para isso uma prévia filtração. Usamos aqui, 10 peixes em cada lote, e um volume líquido também de $300 \mathrm{~cm}^{3}$. Os resultados obtidos foram aproximadamente semelhantes àqueles verificados com a solução recentemente preparada.

$\left.1^{\circ}\right)$ - Na temperatura de $15^{\circ} \mathrm{C}$ aos $35 \mathrm{~m}$. morreram os primeiros peixes (7), e aos $45 \mathrm{~m}$. os restantes.

$2^{\circ}$ ) - Na temperatura de $20^{\circ} \mathrm{C}$, aos $25 \mathrm{~m}$. morreram os primeiros peixes (5), e aos $35 \mathrm{~m}$. os restantes.

$\left.3 .^{\circ}\right)$ - Na temperatura de $25^{\circ} \mathrm{C}$, aos $13 \mathrm{~m}$. morreram os primeiros peixes (6), e aos $16 \mathrm{~m}$. os restantes.

Como era de esperar a temperatura mais elevada $\left(25^{\circ} \mathrm{C}\right)$ abreviou a ação tóxica das substâncias que permanecendo em solução por 2 dias na temperatura do laboratório e em vaso aberto, não perdeu em nada a sua eficácia.

C) - Pesquiza destinada a verificar a capacidade de restabelecimento dos peixes.

Nesta experiência, a medida que as fases iam se sucedendo, retirávamos um determinado número de peixes que eram prontamente colocados em água. 
Solução de saponina pura a $1 / 1000$. Preparação recente.

Número de peixes: 30

Volume líquido: 1 litro

Temperatura: $20^{\circ} \mathrm{C}$

a) $-1 .^{\mathrm{a}}$ fase: $1 \mathrm{~m}$. após a imersão. Aos $2 \mathrm{~m}$. retiramos 4 peixes. Restabelecimento $2 \mathrm{~m}$. após. Aos $4 \mathrm{~m}$. retiramos mais 4 peixes. Inicialmente vão à tôna do líquido. Restabelecimento $14 \mathrm{~m}$. após a imersão.

b) $-2{ }^{\text {a }}$ fase: Aos $7 \mathrm{~m}$. Aos $8 \mathrm{~m}$. retiramos 4 peixes. Permanecem na superfície livre do liquido. Doze minutos após a imersão, voltam a nadar como normais: $37 \mathrm{~m}$. após voltam à superfície, para daí passarem sucessivamente às outras fases, morrendo uma hora e quinze minutos após a imersão em líquido isento do tóxico.

c) - 3. ${ }^{\text {a }}$ fase: Aos $15 \mathrm{~m}$. Aos $18 \mathrm{~m}$. retiramos 4 peixes. Inicialmente permanecem na tôna do líquido. Aos $12 \mathrm{~m}$. começam a entrar sucessivamente, um após outro, na $4 .^{\mathrm{a}}$ fase, para virem a morrer aos $45 \mathrm{~m}$. após a imersão em água isenta do tóxico.

d) - 4. ${ }^{\mathrm{a}}$ fase: aos $20 \mathrm{~m}$.

e) - 5. ${ }^{\text {a }}$ fase: Primeiros mortos aos $30 \mathrm{~m}$. Todos mortos aos $40 \mathrm{~m}$.

Notamos, por meio desta experiência, que a capacidade de restabelecimento só foi possível quando os peixes foram retirados durante a 1. ${ }^{2}$ fase, isto é na de excitação. Os retirados durante as demais fases não sobrevivem embora resistam por espaço de tempo maior que o daqueles mantidos na solução do tóxico.

D) - Pesquiza com o macerado aquoso de frutos de saboneteira (Sapindus saponaria).

$\left.10^{\circ}\right)$

Macerado aquoso de frutos de saboneteira (Sapindus saponaria), preparado segundo téenica já descrita.

Número de peixes: 6

Volume líquido: $300 \mathrm{~cm}^{3}$

Temperatura: $20^{\circ} \mathrm{C}$

a) $-1 \cdot^{\mathrm{a}}$ fase: $30 \mathrm{seg}$. após imersão

b) - 2. ${ }^{\mathrm{a}}$ fase: aos $3 \mathrm{~m}$.

c) $-3 .^{\mathrm{a}}$ fase: aos $5 \mathrm{~m}$.

d) - 4. ${ }^{\mathrm{a}}$ fase: $\operatorname{aos} 10 \mathrm{~m}$.

e) $-5 .^{\mathrm{a}}$ fase: (Primeiros mortos aos $13 \mathrm{~m}$. Todos mortos aos $18 \mathrm{~m}$.)

2. $)$ -

O mesmo macerado utilizado na experiência anterior, 48 horas envelhecido, sofrendo apenas prévia filtração.

Número de peixes: 10

Volume líquido: $300 \mathrm{~cm}^{3}$

Temperatura: $20^{\circ} \mathrm{C}$

a) $-1 .^{\mathrm{a}}$ fase: imediatamente após imersão

b) $-2 .^{\mathrm{a}}$ fase: aos $2 \mathrm{~m}$.

c) $-3 \cdot^{\mathrm{a}}$ fase: aos $4 \mathrm{~m}$.

d) $-4 .^{\mathrm{a}}$ fase: aos $7 \mathrm{~m}$.

e) - 5. ${ }^{\mathrm{a}}$ fase: (Primeiros mortos aos $10 \mathrm{~m}$. Todos mortos aos $14 \mathrm{~m}$.) 
Pelo exposto o macerado aquoso de frutos de Sapindus saponuria, feito na proporção equivalente a uma solução de saponina a $1 / 1000$, mostrou-se muito mais ativo do que esta última.

II) EXPERIMENTAÇÃO COM ACARÁS (Geophagus sp.)

(A-fim-de se observar a ação tóxica em peixes de porte maior)

Saponina pura em solução a 1/1000. Preparação recente.

Número de peixes: 3 . Aproximadamente com $9 \mathrm{~cm}$. de comprimento e $8 \mathrm{~g}$ de pêso.

Volume líquido: 3 litros

Temperatura: $21^{\circ} \mathrm{C}$

a) - Aos $4 \mathrm{~m}$. início da $1 .^{\mathrm{a}}$ fase intercalada por períodos de repouso no fundo do aquário.

b) - Aos $6 \mathrm{~m}$. procuram a superfície livre do líquido, ai ficando por alguns instantes, e voltam então para o fundo onde permanecem imóveis (2. ${ }^{\mathrm{a}}$ fase).

c) - Aos $12 \mathrm{~m} .3{ }^{\mathrm{a}}$ fase. Aos $14 \mathrm{~m}$. imóveis no fundo do aquário, mas em posição anormal, principalmente, em decúbito lateral; se tocados dão fàcilmente uma volta completa em torno do seu eixo longitudinal. Fenômenos tais serão devidos talvez a impossibilidade dos peixes coordenarem os movimentos de suas nadadeiras. Notamos ainda nesta altura da prova a opacidade da córnea. Aos $18 \mathrm{~m}$., se excitados mecanicamente, nadam com movimentos desordenados e vagarosos, para logo voltarem ao estado anterior. De quando em quando, se forem excitados vêm à tôna por meio de movimentos desordenados, porém rapidíssimos, para logo depois cairem no fundo do aquário. Por vêzes êsses movimentos são tão intensos que fazem emergir parte do corpo do animal. Neste estado permanecem até aos $35 \mathrm{~m}$. da experiência.

d) - Aos $40 \mathrm{~m}$. início da $4{ }^{\mathrm{a}}{ }^{\mathrm{f}}$ fase.

e) $-5 \cdot^{a}$ fase: morte aos $60 \mathrm{~m}$.

Como vemos, na concentração de $1 / 1000$, a saponina ainda é tóxica para o peixe acará (Geophagus sp.) de porte bem maior que o pèixe guarú (Poecilia sp.), embora, como é natural, o primeiro se apresente mais resistente à ação do tóxico.

\section{RESUMO}

A experimentação foi efetuada quer com soluções de saponina quer com macerado aquoso de saboneteira (Sapindus saponaria). A atividade dêste, em soluções equivalentes à solução a um por mil de saponina J. D. RIEDEL, mostrou-se muito maior não evidenciando o envelhecimento das soluções, alterações do efeito tóxico. Observaram que a ação tóxica de tal veneno sôbre certos gêneros de peixes (Geophagus $s p$. e Poecilia $s p$.) se manifesta por cinco fases sucessivas - excitacão; asfixiamento; depressão inicial; depressão adiantada; morte e que o tempo decorrente entre elas é variável. Tais variações de- 
monstraram-se influenciáveis pela concentração da saponina ou do macerado de saboneteira, sendo igualmente dependentes do porte do animal.

A temperatura mais elevada, segundo observações feitas a $15^{\circ}$, $20^{\circ}$ e $25^{\circ} \mathrm{C}$., implica num encurtamento dos períodos das diversas fases, enquanto o estado de jejum não parece ter significado para a mais pronta evidenciação dos efeitos esperados.

A capacidade de restabelecimento dos peixes só é possível se retirados na primeira fase das manifestações tóxicas; quando retirados em qualquer das outras quatro fases subsequentes, não houve sobrevivência de nenhum dêles.

\section{SUMMARY}

The experience were made either with saponina solutions or with aqueous maceration of "saboneteira" (Sapindus saponaria).

The activity o this macerations equivalent to $1^{\circ} \%_{00}$ saponin solution J. D. Riedel, was greater and old solutions did not show modifications of toxic effects. The authors observed that the toxic effect of such venon on some fish genera (Geophagus sp. and Poecili a s p.) manifested itself by five sucessive phasis - excitation; asphyxy; initial depression; advence depression; death - and that the time that elapsed among them is a variable one. Such variations are influenced by saponin concentration of by "saboneteira" maceration, and they are dependent on the animal size.

$A$ higher temperature, as it was observed at $15^{\circ} \mathrm{C}, 20^{\circ} \mathrm{C}$ and $25^{\circ} \mathrm{C}$, induce a shortning of periods of the several phasis, but fasting seem not to have interference with the readiest evidence of the expected effects.

The recovery fishes capacity is possible only if they are drown back during the first phasis of the toxic manifestations: if they were drown back in any of the others following four phasis, they do not survive. 